${ }^{1}$ Universidade Estadual do Piauí UESPI, School of Dentistry, Department of Clinical Dentistry, Area of Integrated Clinic, Parnaíba, PI, Brazil
Corresponding author: Ana de Lourdes Sá de Lira Universidade Estadual do Piauí, Faculdade de Odontologia Rua Senador Joaquim Pires 2076 Ininga.

Fone (86) 999595004

CEP: 64049-590 Teresina-PI-Brasil email: anadelourdessl@hotmail.com

\section{Dental caries in children on deciduous dentition: art and socioeconomic aspect}

\author{
Ana de Lourdes Sá de Lira ${ }^{*}$, Sabrynna Gonçalves
} Candeira Portela ${ }^{1}$
Aim: Determine the prevalence and incidence of dental caries in children's deciduous teeth, who were treated with ART technique. Methods: In T1, 62 children were examined for being between 3 and 6 years of age. A questionnaire was applied to the parents or guardians of the children involved in the research, to analyze their knowledge about eating habits and oral hygiene. An intra-oral examination of children from 3 to 6 years old was carried out and dental treatment was performed by the ART technique. Six months after,(T2), the clinical examination was redone to investigate the stability of restorations. Results: In T1, 94 caries cavities were found in 19 children and 86 were recommended for restoration with ART. In T2, 58 restorations were damaged or lost and 15 children had 20 new caries cavities. Conclusion: The prevalence of dental caries in the deciduous dentition was $38.8 \%$ and the incidence was $31.9 \%$. In $\mathrm{T} 2$, the majority restorations class I and II were damaged or lost. ART technique is an option, despite the high failure in ART, especially for child population with deciduous teeth that has limited access to dental services. However, restorations should be supervised and healthy eating habits implemented.

Keywords: Pediatric Dentistry. Dental Caries. Oral Hygiene. 


\section{Introduction}

The prevalence of caries has declined, but it is more significant in the most favored populations, which have a lower CPO-D and a higher number of children without caries ${ }^{1-3}$ Maintaining good oral hygiene is essential so that the individual does not acquire caries disease. This is justified by the dental biofilm, which is the determining factor for the disease to occur ${ }^{4,5}$. But also, to reduce this situation, it is important to take greater care with the children through health promotion measures and prevention ${ }^{6-7}$. The World Health Organization (WHO) has stated that health is also related to schooling, so it is clear that increasing school performance leads to improvements in the health of individuals ${ }^{8}$.

The definition of early caries can be determined by the presence of decayed teeth (even those without cavity), dental elements lost due to caries or restorations, in individuals with a maximum age of 71 months. In addition, any carious surface is defined as severe precarious caries in children under three years of age ${ }^{9}$. Seeking to change reality, promotion measures should be instituted together with other collective health actions, such as preventive, curative, health education and control ${ }^{10}$.

One option for caries disease control is Atraumatic Restorative Treatment (ART), which was devised in the 1980s by Dr. Jo E. Frencken. This method is of minimal intervention that aims to paralyze the carious process and provide favorable conditions to restore oral health ${ }^{11}$.

In accordance with the current objectives of Dentistry (prevention, promotion, early and conservative intervention in the carious lesions), the ART technique should not be considered only an alternative restorative technique, but as a promotion strategy of oral health that aims to take the dental treatment to the non-assisted populations, adapting itself to the reality of them. Therefore, this treatment associates educational actions and preventive health care for the population, as well as curative actions through the removal of carious tissue with instruments, and restoration of the cavity ${ }^{12}$.

It is believed that early dental caries, in the deciduous denture is a public health problem with high prevalence and incidence rates, and that few children have easy access to public dental care. This type of treatment also seeks to respect one of the main current concepts of dental practice, which is to create a favorable environment that halts the caries disease process by means of minimum intervention and maximum preservation of dental structures. In addition to the curative aspect of cavity preparations and restorations, there are the added advantages of concern focused on health promotion, education and patient motivation. So it was decided to carry out this research to determine the prevalence and incidence of dental caries in children in the deciduous denture, who were treated during this research with ART technique.

\section{Material and Methods}

This study was approved by the Research Ethics Committee of the State University of Piauí - CEP / UESPI, under CAAE number: 51011015.4.0000.5209. The principle of ethics was based on the norms contained in Resolution No. 466/12 (CNS/MS). The researcher was provided with the Consent Term for the directors of the School 
Units, authorizing the development of the research after ethical appreciation of the Research Ethics Committee of the State University of Piauí - CEP/ UESPI.

Inclusion criteria were children with caries in the deciduous dentition, in the age range of 3 to 6 years, whose parents or guardians accepted the research. This age group of research was chosen due to the greater probability of the children being with the deciduous complete dentition and attending the preschool. Children less than 3 years of age or older than 6 years of age or who were already in the mixed dentition were excluded from the study because the focus was on the deciduous dentition and those that the parents or guardians did not authorize to participate in the study.

According to the sample calculation, only 45 children should be examined, but it was decided that all 62 children would be examined for being between 3 and 6 years of age. However, 13 were excluded because they were in the mixed dentition. Preventive activities of supervised brushing and topical application of fluoride were performed for children who were excluded from the study, since no oral pathology was present.

The individuals involved were oriented on the objectives of the research and their methods through the Informed Consent Term (TCLE) and the Informed Consent Term (TALE), signed by parents / guardians and children, respectively.

Prior to the execution of the research, the questionnaire was applied to 10 parents, after validation, having been previously applied to 10 parents, and the clinical examination was carried out in 10 children, aged between 3 and 6 years, in the deciduous dentition, attended at the Pediatric Dentistry Clinic of the Dental UESPI, in Parnaíba, chosen randomly for calibration of the researcher student.

At the first moment of the research (T1) a lecture was given to the 49 parents or guardians for awareness and instruction according to the research objectives. The questionnaire was applied. The researcher performed the intra-oral examination of the sample, children enrolled in the Preschools and the Municipal School of Early Childhood Education Tio Zeca, in search of caries lesions with cavity, the majority $(n=26)$ between 5 and 6 years of age. The individual examination was carried out in the schoolyard, under natural light, using wooden spatula and mouth mirror. When present, the teeth and faces were recorded on the patient's record cards. Teeth with evident pulp involvement or painful symptomatology and / or presence of edema or fistula were excluded from the study and immediately referred to the Clinical School of Dentistry of UESPI for endodontic and restorative treatment. The prevalence (T1) and later the incidence of caries (T2) in the sample studied were determined.

Subsequently dental treatment was performed by the ART technique, in the school environment, under natural light. Vitro Molar (Nova DFL, Rio de Janeiro, Brazil) was used as the glass ionomer cement (CIV), because it is one of the materials of choice for this technique, because it has high viscosity, better strength and good mechanical properties $^{13}$. The technique of ART ${ }^{11}$ consisted in detail in:

A. Cleaning of the dental surface with friction with a cotton dressing;

B. Access to caries lesion, if there is enamel without support, with axes, hoe or gingival margin trimmer; 
C. Removal of carious dentin with sharp curettes, starting from the edges of the cavity, maintaining the dentin that leaves in flakes or scales in the portion closest to the pulp (affected dentin);

D. Cleaning the cavity with the liquid of the restorative material, with cotton dressing for 15 seconds on the surface to remove the dentin sludge;

E. Washing with cotton swabs moistened with water (minimum 3);

F. Drying with dry cotton;

G. Dosing and manipulation of the CIV for 30 seconds according to the manufacturer's recommendation;

$\mathrm{H}$. Insertion of the restorative material into the cavity, when it was in the consistency of shiny wire, with insertion spatula, in increments. Leaving with slight excess;

I. Solid vaseline was pressed for 30 seconds in the surface of the restoration;

J. Use of Hollemback spatula or sharp curette to remove excess;

K. Protection of the surface of the restoration with solid petroleum jelly;

L. Use of carbon paper for checking the occlusion;

M. Removal of premature contacts with Hollemback or sharp curette.

Caries lesions included in the ART intervention, according to the nomenclature of Black $^{13}$, comprised those that were in teeth:

1. Later Class I and II;

2. Previous Class III;

3. With loss of cusps;

4. Posterior and anterior Class $\mathrm{V}$

After 6 months (T2), 47 children were again examined to see if there was improvement in oral health, two of them no longer studied in one of the schools. The evaluation criteria for the control of oral health status were based on Ferreira et al. ${ }^{11}$. As explicit in Table 1, in which 0 was considered as indicative of successful treatment and 1 to 3 to indicate intervention failure.

The data were tabulated and analyzed by the SPSS statistical program, version 21 . The Chi-square association test was performed to verify if there were significant differences in the results found. Descriptive statistics (measures of central tendency and dispersion) and construction of graphs were used in order to illustrate the findings of this research.

Table 1. Criteria for Evaluation of Restorations with ART ${ }^{11}$

\begin{tabular}{ll}
\hline Satisfactory ART & 0 \\
\hline Present, minor defects in the margin and / or wear of 0.5mm depth & 1 \\
\hline Partial loss of restorative material & 2 \\
\hline Total loss of restorative material & 3 \\
\hline Absent or loss of tooth by exfoliation & $X$ \\
\hline
\end{tabular}




\section{Results}

The parents were on average 30 years and 10 months old, the majority were single $(n=25)$. In terms of schooling, there were similar numbers who declared that they only had incomplete secondary education $(n=16)$, and those with up to the 4 th grade $(n=16)$. The family income of 1 to 2 minimum wages was informed by 39 parents.

At the first moment, when asked if they had already participated in any lecture on oral health, 34 answered yes. Upon receiving oral hygiene instructions from the children, 37 reported having received some guidance. Of these, 23 were passed on by dentists and others by other professionals, relatives and / or friends. In relation to the habit of doing the oral hygiene of the children, the majority answered yes $(n=42)$, being executed 3 times a day, according to 26 of these. In addition, he was asked if his children used to sleep without doing oral hygiene. Of this, 33 answered to do it and 18 reported not doing the hygiene of the child before bed.

Information about the children's diet, milk consumption and sucking habit were collected. In this way, 41 children do not use sugary pacifiers, most have healthy meals, but they included sugary foods in the snack, in addition to the intake of artificial milk. After the lectures, parents acknowledged that oral hygiene and healthy eating may decrease the chances of developing caries disease.

In the first intervention period (T1) by ART, 19 children out of 49 in the sample had caries lesions, 9 of which were female and 10 were male. The prevalence of dental caries in the deciduous dentition was $38.8 \%$.

In these 19 children, 94 decayed teeth were diagnosed, of which 86 were restored (8 teeth presented great destruction by caries, with indication of exodontia, and were later performed in the UESPI School of Dentistry Clinic), corresponding to 42 Class I restorations, 22 of Class II, 17 of Class V and 5 of Class III.

According to Figures 1 and 2 it was observed in T1 that the second deciduous molars were the ones that presented the highest number of carious lesions.

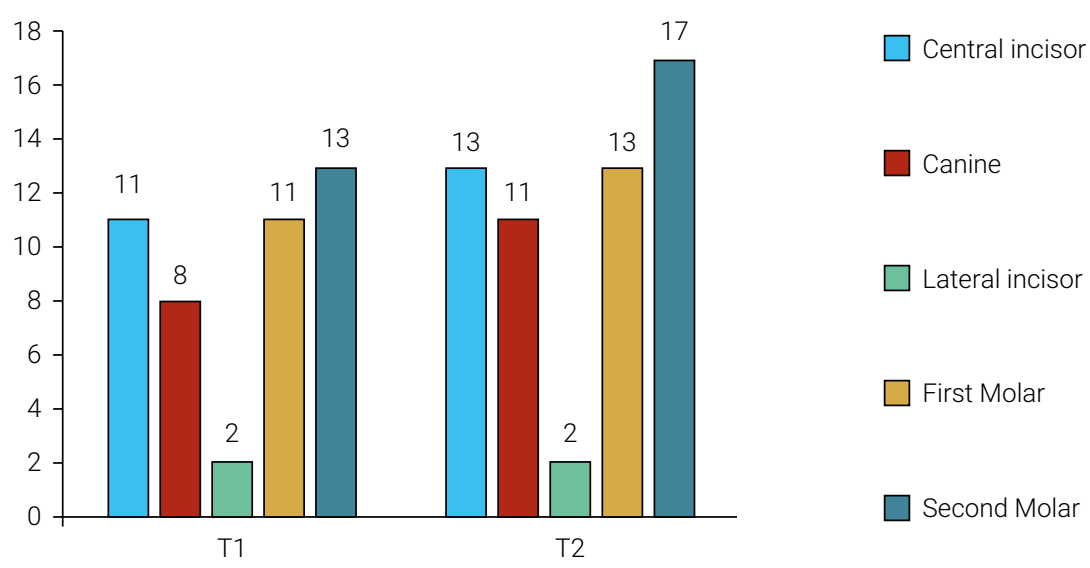

Figure 1. Upper deciduous teeth with carious lesions. Parnaíba-PI. 2016. 


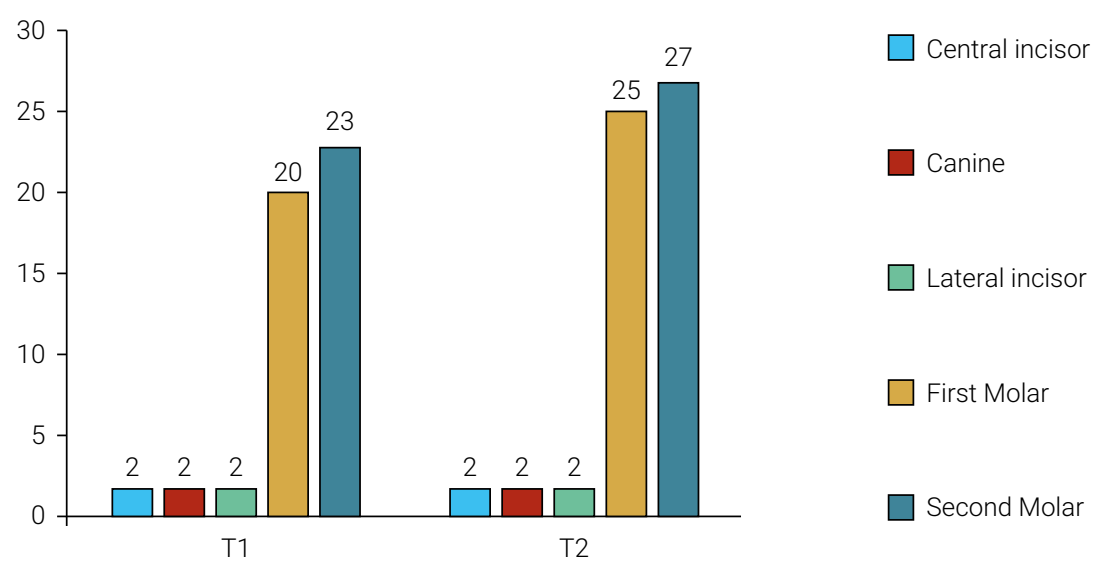

Figure 2. Lower deciduous teeth with caries lesions. Parnaíba-PI. 2016.

Twenty new cavity lesions were observed in 15 of these 17 children, being 11 of Class I and 9 of Class II, corresponding to incidence of dental caries of $31.9 \%$.

Among these 15 preschoolers, it was found that in 12 of them only a new carious lesion was found, but 2 presented with two lesions and one with 4.

According to Figure 3, it was verified that 58 of the 86 restorations performed on T1 had failed after 6 months (T2).

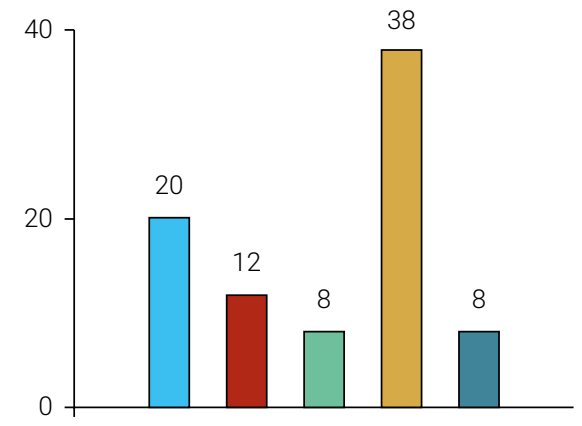

Satisfactory ART

$\square$ Present, with defects of $0.5 \mathrm{~mm}$

Partial loss

Total loss

Absent tooth

Figure 3. Evaluation criteria of ART control. Parnaíba-PI. 2016.

Of the 58 compromised restorations, there were partial loss of 6 Class I and 2 Class II restorations, and total loss of 15 Class II and 23 Class I restorations. All 17 Class III and Class III restorations performed remained Satisfactory. Five of Class II and 7 of Class I presented defects of $0.5 \mathrm{~mm}$.

The failures in ART restorations were highly significant when the Chi-square test $=27.3002 ; \mathrm{Gl}=3$; With $p<0.001$. Therefore, if other dental restorations have been made under the same conditions, teeth are expected to be divided equally into each of the scores adopted in the survey. The number of teeth in each score did not happen at random. 


\section{Discussion}

In this study it was observed that families had low monthly schooling and income. These data corroborate with those found in another study, 15 in which a family income of up to two minimum wages predominated (98.3\%), and $76.6 \%$ of the parents / guardians declared having only complete elementary education.

It is essential to make parents or caregivers aware of the importance of oral health of children with guidelines on how to maintain it, including oral hygiene before bed, dental care before 12 months of age to limit or prevent cases of early decay, as well as the integrated assistance of health professionals: surgeon-dentist and pediatrician ${ }^{13,14}$.

In the study carried out by Robles et al. ${ }^{15}$, the mothers reported having knowledge about the importance of brushing after meals, the relationship between the high carbohydrate diet and the development of caries and its consequences. The guidelines received from pediatricians, nurses and other mothers diverged from this research, in which it was found that the dentist was the one most responsible for disseminating these instructions. The children had a diet based on healthy foods, the parents did the hygiene of the children, mostly three times a day. But despite this, there were a large number of children affected by early caries, probably because they used sugar in the snack, both in T1 and T2.

According to Almeida et al. ${ }^{16}$, it was not possible to notice a direct and expressive relationship between the daily frequency in the consumption of sweet foods with the caries index. In the same way, it could not be said that the experience of caries and the number of toothbrushes are inversely proportional. In the study by Ribeiro et al. ${ }^{17}$ 224 children were part of a control for four years, and it was found that brushing was not an expressive factor for individuals not to have caries, since $40.4 \%$ of children who brush their teeth and more than half (53.4\%) of those who did not brush had caries.

Early caries brings physical and psychological consequences, since it interferes in the quality of life ${ }^{18}$. This can be explained by the progression of the disease, as abscesses may appear, damage of permanent teeth, painful symptomatology, feeding, swallowing, breathing damages ${ }^{19}$.

Initially, it manifests itself through white and opaque patches, but with progress, the clinical aspects become cavities. As it is acute, if there is no intervention, there will be total loss of the dental crown. The most affected elements are the upper and lower anterosuperior and molars. Anteroposterior teeth are included in more advanced cases of caries disease ${ }^{20}$.

The second deciduous molars were the teeth most affected by caries (Figures 1 and 2). These findings are in agreement with Rigo et al. ${ }^{21}$ when affirming that dental elements $55,65,75$ and 85 presented the highest caries in 56\%,55\%,46\% and $45 \%$ of the cases, respectively. As an alternative treatment in situations of low socioeconomic level and high occurrence of caries, ART has good results because it includes, among others, less invasive care in established caries lesions and oral health guidelines and it is well accepted by children 22 .

According to data collected 6 months after the intervention with ART, there was a high number of total loss of the restorations (Figure 3). A similar result was found by Pazuch et al. ${ }^{23}$ in which more than half of the restorations (62.5\%) performed 
needed repair after 6 months. These results occurred with CIV, which is the material of choice in ART practice, due to its properties, such as: fluoride release and physicochemical adhesion.

It is believed that the high failure rate in treatment and the increase in the number of carious lesions may have been due to the absence of cavity preparation, such as removal of carious tissue by means of drills, associated with insufficient relative isolation to avoid contact of the CIV with fluids and inadequate conditioning of the children. Sales et al. ${ }^{24}$ also justified their failure to condition and control the child during care.

The incidence of caries in T2 occurred in children whose parents reported that they did not brush their teeth before bed, although most did so after meals. Probably the consumption of sweets in the intervals of meals, even at low frequency, associated with the absence of brushing at bedtime have favored the appearance of new caries. Failure to remove bacterial biofilm and low salivation during sleep predispose to the appearance of carious lesion ${ }^{25,26}$.

A greater number of brushing provides a better chance of avoiding the development of the carious process ${ }^{27}$. There are factors that favor the installation of early caries, such as: sucrose-rich diet, cariogenic microbiota, oral hygiene efficiency and the time the food stagnates on the teeth ${ }^{28}$.

The restorations that failed after 6 months were those of Class I and Class II, corroborating with the findings of other authors ${ }^{25-28}$, who verified that occlusal-proximal restorations (Class II) have higher rates of failure, since they are more favorable to fractures and complete loss. It can be explained by the failure to adapt the CIV to the cavity due to its viscous texture and low flow, allowing the appearance of spaces inside the restoration, consequently reducing its longevity. Other physical characteristics of this cement also influence the success of ART as low mechanical properties, high solubility and porosity ${ }^{28}$.

It was noted that the results of the questionnaires diverged in some questions from what had been found in the intra-oral examination of preschool children. Although the parents / guardians had notions of hygiene and eating habits, there was a high prevalence and incidence of caries and failure of the restorations performed with CIV by the ART technique.

It was concluded that there was a high prevalence of caries in the deciduous dentition (38.8\%), which may be related to socioeconomic factors and the need for greater efforts to expand dental care with oral health promotion and prevention actions.

The parents were advised on the measures to be taken to prevent tooth decay.

In T2, six months after restorative ART treatment, most Class I and II restorations were damaged or lost, probably due to the large cavities and the limitation of the technique. Class III and $\mathrm{V}$ restorations remained satisfactory. There was a high incidence of Class I and II caries (31.9\%) in 15 of 17 children in whom oral hygiene was not performed before bedtime.

ART technique is an option, despite the high failure in ART, especially for child population with deciduous teeth that has limited access to dental services. However, restorations should be supervised and healthy eating habits implemented. 


\section{The interpretation of the results should consider some limitations inherent in this study. It is important that future studies be carried out on the treatment and control of dental caries in the deciduous dentition.}

\section{References}

1. Rezende LN, Santos FCS, Neto MS, Santos F. [Feeding rampant caries in children aged 2 to 5 years: literature review]. J Manag Prim Health Care. 2014;5(2):219-29. Portuguese.

2. Oliveira LB, Moreira RS, Reis SCGB, Freire MCM. Dental caries in 12-year-old schoolchildren: multilevel analysis of individual and school environment factors in Goiânia. Rev Bras Epidemiol. 2015 Jul-Sep;18(3):642-54. doi:10.1590/1980-5497201500030010.

3. Scalioni FAR, Figueiredo SR, Curcio WB, Alves RT, Leite ICG, Ribeiro RA. [Early Childhood Dietary and Caries Habits in Children Attended by Brazilian Dentistry School]. Pesq Bras Odontoped Clin Integr. 2012;12(3):399-404. doi: 10.4034/PBOCI.2012.123.16. Portuguese.

4. Santos APP, Soviero VM. [Assessment of the quality of oral hygiene in infants and preschool children: importance and methods: literature review]. Rev Clín Pesq Odontol. 2008;4(2):87-92. Portuguese.

5. Moura LFA, Moura, M. S, Toledo OA. [Knowledge and practices in oral health of mothers who attended a dental program of maternal and child care]. Cienc Saude Colet. 2007; 12(4):1079-1086 doi: 0.1590/S1413-81232007000400029. Portuguese.

6. Aquilante AG, Almeida BS, Castro RFM, Xavier CRG, Peres SHCS, Bastos JRM. [The importance of dental health education for preschool children]. Rev Odontol UNESP. 2003;32(1):39-45. Portuguese.

7. Souza LM, Macedo A, Gusmão RCMP, Athayde ACR, Costa LED, Queiroz FS, et al. [Oral Health in School and Family: from Autonomy to Social Transformation]. Rev Bras Educ Med. 2015;39(3):426-32. Portuguese.

8. Navarro MFL, Leal SC, Molina GF, Villena RS. [Atraumatic Restorative Treatment: news and perspectives]. Rev Assoc Paul Cir Dent. 2015;69(3):289-301. Portuguese.

9. Garbin CAS, Sundfeld RH, Santos KT, Cardoso JD. [Current Aspects of Atraumatic Restorative Treatment]. RFO. 2008;13(1):25-9. Portuguese.

10. Santos MMPR, Mathias IF, Diniz MB, Bresciani E. [Evaluation of the surface hardness of glass ionomer cements reinforced by carbon nanotubes]. Rev Odontol UNESP. 2015;44(2):108-12. doi: 10.1590/1807-2577.1060. Portuguese.

11. Ferreira LL, Ferreira-Nóbilo NP, Gibilini C, Sousa MLR. Longevity of atraumatic restorations performed by undergraduate dentistry students. Rev Odontol UNESP. 2014;43(4):241-4. doi: 10.1590/rou.2014.039.

12. Aguiar YPC, Dantas DCRE, Ribeiro AIAM, Lima RF, Sousa YC, Guênes GMT. [Clinical evaluation of glass ionomer restorations in children]. RF0.2014;19(1):70-6. doi: 10.5335/rfo.v19i1.3628. Portuguese.

13. Castilho ARF, Mialhe FL, Barbosa TS, Puppin-Rontani RM. Influence of the family environment on the oral health of children: a systematic review. J Pediatr. 2013;89(2):116-23. doi: 10.1016/j.jped.2013.03.014.

14. Lemos LVFM, Zuanon ACC, Myaki SI, Walter LRF. [Experience of dental caries in children attended in a program of Dentistry for babies]. Einstein. 2011;9(4):503-7. doi: 10.1590/S1679-45082011A02184. Portuguese.

15. Robles ACC, Grosseman S, Bosco VL. [Practices and meanings of oral health: a qualitative study with mothers of children attended at the Federal University of Santa Catarina]. Cienc Saude Colet. 2010;15(Suppl 2):3271-81. doi: 10.1590/S1413-81232010000800033. Portuguese. 
16. Almeida AL, Barbosa AMF, Menezes VA, Granville-Garcia AF. [Caries experience among mothers and children: influence of socioeconomic and behavioral factors]. Odontol Clín Cient. 2011;10(4):373-9. Portuguese.

17. Ribeiro AG, Oliveira A F, Rosenblatt A. [Early childhood caries: prevalence and risk factors in preschool children at 48 months in the city of João Pessoa, Paraíba, Brazill. Cad Saude Pública. 2005;21(6):1695-700. doi: 10.1590/S0102-311X2005000600016. Portuguese.

18. Lemos LVFM, Correia MF, Spolidório DMP, Myaki DMP, Zuanon ACC. [Cariogenicity of Breast Milk: Myth or Scientific Evidence]. Pesq Bras Odontoped Clin Integr. 2012;12(2):273-8. doi: 10.4034/PBOCI.2012.122.18. Portuguese.

19. Feitosa S, Colares V. [The Repercussions of Early Childhood Caries in the Quality of Life of Pre-School Children]. Rev Ibero-Am Odontopediatr Odontol Bebê. 2003;6(34):542-8. Portuguese.

20. Losso EM, Tavares MCR, Silva JYB, Urban CA. [Early and severe childhood caries: an integral approach]. J Pediatr. 2009;85(4):295-300. doi: 10.1590/S0021-75572009000400005. Portuguese.

21. Rigo L, Souza EA, Junior, AFC. [Experience of dental caries in the first dentition in a municipality with water fluoridation]. Rev Bras Saúde Matern Infant. 2009;9(4):435-42. doi: 10.1590/S1519-38292009000400008. Portuguese.

22. Raggio DP, Imperato JCP, Politlano GT, Echeverria SR, Uemura ST, Ferreira EMS. [Atraumatic Restorative Treatment]. RGO. 2004;52(5):355-8. Portuguese.

23. Pazuch J, Zottis M, Perussolo B, Patussi EG, Pavinato LCB, Bervian J. [Evaluation of the clinical performance of ART restorations (Atraumatic Restorative Treatment)]. RFO. 2014;19(1):88-93. doi: 10.5335/rfo.v19i1.3694. Portuguese.

24. Sales Peres SHC, Hussne R, Perer AS. [Atraumatic Restorative Treatment (ART) in children aged 4 to 7 years: clinical evaluation after six months]. Rev. Inst Ciênc Saúde. 2005;23(4):275-80. Portuguese

25. Eleutério ASL, Cota ALS, KOBAYASHI TY, Silva SMB. [Clinical Evaluation of Oral Health of Children of the Municipalities of Alfenas and Areado, Minas Gerais, Brazil]. Pesq Bras Odontoped Clin Integr. 2012;12(2):195-201. doi: 10.4034/PBOCI.2012.122.07. Portuguese.

26. Deliberali FD, Brusco EHC, Brusco L, Perussolo B, Patussi EG. [Behavioral factors involved in the development of early caries in children attended at the Pediatric Dentistry Clinic of the School of Dentistry of Passo Fundo - RS, Brazil]. RFO. 2009;14(3):197-202. Portuguese.

27. Goes MF, Martins AL, Sartori CG, Sinhoreti MAC. [Solubility of glass ionomer cements indicated for Atraumatic Restorative Treatment]. Rev Assoc Paul Cir Dent. 2015;69(3):272-8. Portuguese.

28. Yip HK, Smales RJ. Tay FR. Chu FCS. Selection of restorative material for the atraumatic restorative treatment (ART) approach: a review. Spec Care Dentist. 2001;21(6):216-21. doi: 10.1111/j.1754-4505.2001. 